\title{
Editorial
}

\section{An Increase in Incidence of ED Presentations in the United Kingdom with Complete Heart Block- COVID-19 Effect?}

\section{Chowdhury*}

Specialty Registrar, Emergency Medicine, UK

\author{
A R T ICLE INFO \\ Article history: \\ Received: 14 December, 2020 \\ Accepted: 29 December, 2020 \\ Published: 14 January, 2021 \\ Keywords: \\ Complete heart block \\ COVID-19 \\ emergency department
}

There seems to an increase in the presentations to our Emergency Department with patients with complete heart block. The important question is whether this is an apparent increase in numbers or a true increase in numbers of presentations remains to be seen. It has been well recognised that across the Emergency Departments in the United Kingdom, there has been a fall in the number of attendances. In some estimates, this has been as low as a $30 \%$ reduction in the number of ED attendances when compared with figures in the previous years.

Get access to the full version of this article: http://dx.doi.org/10.31487/j.JICOA.2021.01.05

\footnotetext{
${ }^{*}$ Correspondence to: D. Chowdhury, Specialty Registrar, Emergency Medicine, UK; E-mail: dc7740.2007@my.bristol.ac.uk 